\title{
O Servidor Público no Judiciário
}

\author{
WALdyr dos SAntos
}

\author{
II — PROCESSO ADMINISTRATIVO
}

E

necessário processo administrativo, com ampla defesa, para demissão de funcionário admitido por concurso" (Súmula 20; $\mathrm{RE}$ 53.307-RS, in DJ 23-6-65, pág. 1.510; RE 10.786-SC, in DI 3-4-63, pág. 766; RE 33.577-SE, in 24-11-65, pág. 3.317).

Assim como, pela atual Carta Política (art. 103), “a demissão sòmente será aplicada ao funcionário: I - vitalício, em virtude de sentenca judiciária; II - estável, na hipótese do número anterior, ou mediante processo administrativo, em que se lhe tenha assegurado ampla defesa".

Assim, foi firmada pelos Tribunais a orientação de que "funcionário, com mais de cinco anos, não pode ser demitido sem prévio processo administrativo" (RMS 14-953-MG, RTJ, volume 37, pág. 18). E no Tribunal Federal de Recursos: "O funcionário estável não pode ser dispensado ou demitido senão em virtude de sentença judiciária ou mediante processo administrativo" (Agravo em Mandado de Segurança AMS 1.458-PR, in DJ 25-9-64. Apenso pág. 803; AMS 15.478-PR, in DJ 14-2-64, Apenso, pág. 166).

Por isso, "a simples sindicância reservada, em que o servidor não foi ouvido, não autoriza a demissão" (AMS 47.661-GB, in
DJ 24-2-67, pág. 337).

O Judiciário não admite também que "funcionário em estágio probatório seja sumàriamente demitido" (RE 51.077, in DJ 18-4-63, pág. 954; RMS 14.581-RJ, in RTJ, volume 33, pág. 337; $\mathrm{RE}$ 46.500-PE, in RTJ, volume 24, pág. 324), consubstanciando em Súmula 21:

"Funcionário em estágio probatório não pode ser exonerado nem demitido sem inquérito ou sem as formalidades legais de apuração de sua capacidade". (Nesse sentido os julgados: Agravo de Instrumento 
38.085-DF, in DJ 20-2-67, pág. 227; RMS 16.743-RJ, in 15-9-67, pág. 2.857; RMS 15.083-RJ, in 30-3-66, pág. 989; RE 47.539-SP, in 17-12-63, pág. 4.441; RMS 15.154-SP, in RTJ, volume 36, pág. 541; RMS 13.122-RJ, in RTJ, volume 35, pág. 158).

O Estágio Probatório é considerado como a estabilidade relativa (RE 14.533-MG, in DJ 23-4 64, pág. 1.508 e RTJ, volume 33, pág. 328).

Assistimos à reação do Judiciário às demissões em massa, decretada, em 1961, por manifestação do STF e TFR:

"Nomeação regular para cargo isolado de provimento efetivo. A demissão não fica ao arbitrio da autoridade, mas depende, em face do estágio probatório, da apuração das qualidades negativas do funcionário para desempenho do cargo" (RE 47.539-SP, in DI 5 3-64, Apenso, pág. 65; RE 57.223-DF, in DJ 22-4-65, pág. 800; RE 56.975-DF, in DJ 22-4-65, pág. 799 e RTJ, volume 32, pág. 437; RE 56.596-DF, in DJ 22 de abril de 1965, pág. 799; Ag. 35.417-DF, in DJ 15-9-65, pág. 2.404; RE 56.596-DF, in RTJ, volume 32, pág. 435; MS 9.150-DF, volume 23, pág. 109 (maioria).

"Demissão em massa. Reintegração. O servidor demitido ilegalmente, como se verificou em fevereiro de 1961 , tem direito a ser reintegrado, sem perda de quaisquer vantagens". (AMS 43.963-GB, in DJ 18-4-66, pàg. 1.214; Apel. Civ. 21.580-DF, in 18 4-66, página 1.216; Ap. 21.658-GB, in 21-3-67, pág. $667-$ maioria; Ap. 51.940-GB, in 22-5-67, pág. 1.472; Ap. 22.548-DF, in 22-5-67, pág. 1.482 - maioria).

O conceito de "ampla defesa", nos dois mais altos Tribunais, se apresenta com a mesma delimitação. 864),

No STF (RE 49.016-PE, in DJ 20-12-62, Apenso, página

"Assegurar ampla defesa, durante o curso do processo administrativo, é submetê-lo às fases de que trata a lei vigente do direito de defesa, concedido ao funcionário; isso não implica a necessidade de imprimir ao inquérito administrativo o mesmo rito do processo contraditório, garantido ao acusado criminalmente (artigo 141, § 25, da Constituição Federal)" (Ribeiro da Costa). 
"Necessário é que se garanta ao acusado ampla defesa, mesmo quando citado no curso do processo, ou após a coleta das provas, ao funcionário se garantirá o direito de reinquirir testemunha, apresentar novas provas, etc." (Victor Nunes Leal).

$\mathrm{E}$, ainda (RMS 8.483, in DI 2-9-61, pág. 1.842),

"Não há cerceamento de defesa do funcionário pela não inquirição de testemunhas cujo depoimento não requereu.

Não é obrigatória a citação do servidor no início do processo, embora nêle possa intervir em qualquer fase". (Victor Nunes Leal).

No TFR (Apelação Cível 13.034-GB, in DJ 14-5-65, Apenso, pág. 211).

"Então sòmente pelo fato de algumas testemunhas terem aludido ao gênio irascivel, intratável do acusado, a comissão de inquérito, apesar de ter concluído que o apelado jamais portou armas em serviço, acrescentou que "se, entretanto não se caracterizou o porte de arma no trabalho, positivou-se, todavia, que o servidor persiste em não observar as normas de trabalho adotada..."

"Houve, assim, um evidente cerceamento de defesa, impossibilitando a que o funcionário se defendesse de outras imputações que se lhe fizeram no Relatório" (Godói Ilha).

“... há um paralelismo entre inquérito administrativo e o processo judicial, embora não sejam rigorosamente as mesmas as formalidades, especialmente depois da Constituição de 1946, que exige para a realização dêsse inquérito amplitude de defesa, e uma das condições de defesa ampla é a formação de um contraditório, constante de uma acusação certa ou de atos incriminados que serão apurados no curso do inquérito". (Oscar Saraiva).

Ainda, "é nulo e não pode sustentar ato demissório o inquérito administrativo em que se não tenha ensejado ampla defesá ao acusado, inclusive quanto ao direito de contraditar a testemunhas". (Ap. 13.034, in DJ de 14-5 65, Apenso, pág. 211 -

Se a citação do servidor não é obrigatória, no início do processo (RMS 8.483 RJ), ela constitui imposição essencial, para a apresentação de defesa, sendo sua omissão causa de nulidade do processo: 
"A citação pessoal da parte que tenha enderêço certo, conhecido, constitui imposição tanto de direito comum como o de especial.

"A citação edital mandada fazer por razões de mera comodidade com infringência de normas legais expres sas e cerceamento do direito de defesa da parte, conduz à conseqüência de nulificar o processo administrativo". (Ministro Moacir Catunda - TFR, Apelação Cível 21.728-GB, in DJ de 13-11-67, pág. 3.741).

Há de se entender que a citação por edital sòmente será válida, após a verificação da impossibilidade da citação pessoal, isto é, a procura do servidor no enderêço que obrigatòriamente deveria constar de seu assentamento funcional, porque até o enderêço eventual tem que ser declarado (arts. 87 e 96 da Lei $n^{\circ}$ 1.711, de 1952).

"Se após ultimada a instrução do processo administrativo, foi feita a citação do indiciado para que apresentasse sua defesa, respeitado está o disposto no artigo 222 do Estatuto dos Funcionários Públicos Civis da Uñião, o qual não contém ofensa ao princípio do contraditório". (AMS 45.447-RJ, in DJ 22-5-67, página 1.467)

"Citação por edital. Nuln o processo administrativo que, após a citação por edital, culminou com a exoneração de servidor por abandono de emprêgo, se, comprovadamente, estava êle em lugar certo e, ainda, tinha estabilidade". (AMS 42.249-DF, in DI 17-2-67, pág. 213).

A irregularidade no processo administrativo tanto pode ser superada no processo judicial (MS 42.920-DF, STF, in DI 8 de junho de 1966 , pág. 1.977), como remediada mediante concessão de segurança (TFR, AMS 30.551 PR, in DI 29 4-66, pág. 1.369).

"A demora na terminação do julgamento não implica em nulificação do processo administrativo, ainda mais quando causada em parte pelo próprio demitido e em parte pelo vulto do que havia a perquirir, investigar". Assim decidiu o TFR, por maioria de votos, na decisão dos Embargos à Apelação Cível 12.118-DF, DJ 18-9-64, Apenso, pág. 775).

São causas da nulidade do processo:

a) a inobservância de formalidade essencial, prejudicando o acusado (AMS 33.150-SE, in DJ 16-9-66, pág. 3.137); 
b) a coação, mesmo moral, sofrida pelo paciente (Apelação Cível 11.702-DF, in DJ 17-12-65, Apenso, pág. 572);

c) a participação na Comissão de Inquérito, de funcionário interino (STF, RE 59.059-MT, in DI de 24 8-67, pág. 2.545). O TFR aceita a participação de interino como vogal (Ap. Cív. 14.520 , in DI 17-3-65, pág. 380), assim como entende:

"Pelo primeiro Estatuto dos Funcionários Públicos Civis da União sòmente os secretários das comissões de inquérito poderiam ser funcionários sem segurança da estabilidade; no Estatuto atual desapareceu a discriminação".

"O Estatuto atual diz que se admite que a comissão possa ser composta de três funcionários ou extranumerários". (AMS 25.762 -DF, in 11-6-63, página 1.699).

Constitui direito:

a) liquido e certo, o de vista da parte em processo administrativo (MS 7.271-DF, MM TFR, in DJ 13-3-64, Apenso, página 257 e AMS 25.796 CE, in DJ i2 -5 67, pág. 1.360);

b) a devolução de documentos, juntos a processos administrativo (AMS 33.358-GB, in DI 6-5-65, pág. 1.473).

A requisição de processo administrativo, por parte do Juízo, suspende, em princípio, o prazo para a contestação (Ap. Cív. 13.963-PR, in DJ 30-8-63). Uma vez efetivada a requisição, não importa ela na anexação do processo administrativo ao judicial, cabendo ao interessado em sua requisição, sòmente, o pedido de certidão das peças que julgar indispensáveis à defesa de seu direito (Ap. Cív. 13.309, in DJ 10-12-64, pág. 4.523).

$O$ inquérito administrativo pode ser repetido, conforme entende o Egrégio Tribunal Federal de Recursos:

"Não tem apoio legal o mandado de segurança interposto com o fim de impedir a instauração de inquérito administrativo, sob alegação de já haverem sido realizados outyos inquéritos destinados à apuração de crime". (AMS 31.816-PA, in DJ 30-9 66, pág. 3.347).

"O afastamento para responder a inquérito autoriza apenas redução dos vencimentos, mas não suspensão do pagamento respectivo" (AMS 31.886-AM, in 21 10-66, pág. 3.689; Apel. Civ. 20.929, in 18-11-66, pág. 4.038, maioria).

Com relação aos inquéritos administrativos cumpre ao Judiciário examinar a competência da autoridade, a observância das 
formalidades legais e o respeito aos limites da penalidade legal mente prevista (RHC 40.196-SC, in DJ 12 12-63, Apenso, página 127; Agr. Inst. STF 29.332, DI 16-7 64, pág. 2.368; Ap. Civ. 15.902-GB, in DJ 18-6-55, Apenso, pág. 283; Res. 166-GB, DJ 26-6-64, Apenso, pág. 510; Ap. Cív. 13.428-DF, DJ 13-12-63, Apenso, pág. 251; AMS 48.484-PR, DJ 14 10-66, pág. 3.564).

"Principio da vinculação ao preceito legal. A inconformidade do ato adininistrativo com a lei, que prevê ato repressivo diverso do que sai praticado, com base nos fatos apurados, autoriza a declaração da ilegalidade do mesmo ato". (Apel. n 20.837-MG, D/ 1 11-67, pág. 3.616).

\section{III - PENALIDADES}

Pela falta residual, não compreendida na absolvição pelo juízo criminal, é admissível a punição administrativa do servidor público (Súmula $n^{9} 18$ ).

Assim, "a sentença absolutória no processo criminal por não existir prova para a condenação, não impede o procedimento disciplinar na instância administrativa "(ERE 50.886-SP, RTJ 141/552 - votos contrários de VB, HL e VNL).

Mas, a absolvição em processo criminal em que não se apurou falta residual, deve acarretar a reintegração do funcionário público demitido (RE 61.416-PE, RTJ 45/792).

Também, o julgamento criminal que absolve por falta de provas não impede processo administrativo nem que, com base nesse processo, a Administração Pública destitua o funcionário encontrado em falta grave (Ag. 27.358-SP, DJ 18-4-63 Apenso, p. 170; RE 61.568-PE, DJ 17-5-68, p. 1.755).

Por sua vez, o habaes corpus contra ela (punição) só poderia caber por incompetência da autoridade, inobservância das formalidades legais que deveriam preceder a imposição da pena, limites legais, etc., não para apreciar o merecimento do ato, sua justiça ou injustiça (RHC 40.196-SC, DJ 12-12-63, Apenso, p. 127).

Da mesma forma, descabe o mandado de segurança contra aplicação de pena disciplinar a servidor, a menos que na medida se argúa a incompetência da autoridade ou a inobservância de formalidade essencial do processo administrativo (RMS 18.656SP, DJ 25-10-68, p. 4.403). 
Porque, contra a aplicação de medida disciplinar, não cabe mandado de segurança (art. 5\%, Lei 1.533-51) (RMS 16.796PI, DJ 4 11 68, p. 4.556).

Assim como a sanção administrativa aplicada ilegalmente não é sanável por habeas corpus nem o vício de punição disciplinar se transfere ao processo criminal (RHC 45.207-PR, DJ 3-5-68, p. 1.494).

\section{Já o Tribunal Federal de Recursos entende:}

"A função do Poder Judiciário, na apreciação das sanções disciplinares impostas pela Administração Pública, não se limita ao exame dos seus aspectos formais de legalidade, mas vai ao mérito, apreciando da justiça e da adequação da pena". (Ap. 15.902-GB, DJ 18 de junho de 1965, Apenso, p. 283).

Igualmente, ainda,

"Ao Poder Judiciário, quando provocado, cabe conhecer e decidir sôbre os resultados de inquéritos administrativos destinados à demissão de funcionários, não apenas quanto aos seus aspectos formais de legalidade, mas sôbre o próprio mérito do decidido (art .141, §4 , da Constituição)". (Res. 166-GB, DJ 26-6-64, Apenso, p. 510).

E o Supremo Tribunal Federal fixa jurisprudência no sentido de que o Mandado de Segurança "não é meio idôneo para se reexaminar matéria de prova em processo administrativo que se aplicou pena disciplinar por autoridade competente" (RMS 14.168-DF, DJ 29-9-65, p. 2.586; RMS 13.184-GB, DI 22 de abril de 1965, p. 795; RMS 15.312 PR, DJ 30-11-66 (página 4.189).

No mesmo sentido, decide o Tribunal Federal de Recursos:

"Ato disciplinar - nos têrmos do art. 5 da Lej $\mathrm{n}^{\circ} 1.533$, de 1951 - é inexaminável através de man. dado de segurança" (AMS 46.687-GB, DJ 2-12-66, p. 4.242).

E, ainda,

"Não cabe mandado de segurança contra medida disciplinar, sobretudo para discutir a justiça do ato". (AMS 35.576-GB, DI 18-4-66, p. 1.212; AMS 46.687GB, DI 2-12-66, p. 4.242; AMS 43.801-CE, DI 8-5-67, p. 1.281).

Aliás, essa orientação judiciária se contém no princípio geral de que 
"Ao Judiciário é defeso apreciar injustiça de ato administrativo, cabendo-lhe tão-sòmente reparar a ilegalidade de que se ache eivado" (RE 58.411-PE, D) 21-9-66, p. 3.200).

E, no Tribunal Federal de Recursos:

"O Poder Judiciário aprecia o ato administrativo, mas apenas do ponto-de-vista da legalidade. A conveniência e oportunidade são áreas que a sentença não penetra". (MS 31.560-DF, DJ 28-4-64, p. 1.072; AMS 32.934, DJ 8-9-64, p. 3.210; Ap. 12.943, DJ 2-9-64, p. 3.139; Ap. 13.436, DJ 20-8-64, p. 2.950; e DI 25-9-64. Apenso, p. 795; Ap. 12.962-GB, DI 24-3-64, p. 623; AMS 39.690-GB, DI 22-8-66, p. 2.765).

\section{1 - DEMISSÃO}

"A demissão de funcionário público, como ato vinculado, é passivel do contrôle jurisdicional, para aferição da existência de abuso de poder ou ilegalidade. Todavia, in casu, torna-se inviável esta apreciação na limitada esfera processual de writ por envolver questão de fato controvertida (STF MS 17.148DF, DJ 13-10-67, p. 3.297; RTJ 43/514).

Os funcionários concursados, assim como os que por qualquer outra forma adquiriram a estabilidade, não podem ser demitidos sem prévio processo administrativo em que se lhes tenha assegurado ampla defesa (Súmula n\% 20; RE 55.307-RS, DI 23-6-65, p. 1.510; RE 10.786-SC, DJ 3-4-63, p. 766; RE número $33-577-\mathrm{SE}$, DI $24-11-65$, p. 3.317; RMS 14.953-MG, RTJ $37 / 18)$.

A demissão do servidor público só pode ser efetivada:

a) pela autoridade competente;

b) na forma prescrita em lei (RMS 12.668-GB, DJ 2 de julho de 1964, Apenso, p. 425).

Funcionário em estágio probatório não pode ser exonerado nem demitido sem inquérito ou sem as formalidades legais de apuração de sua capacidade (Súmula n 21; $\mathrm{Ag}$. 38.085-DF, DJ 20-2-67, p. 227; RMS 16.743-RJ, DI 15-9-67, p. 2.857; RMS 13.122-RJ, DI 24-11-65, p. 3.315, RTJ 35/158; RMS 13.819-RJ, DJ 24-11-65, p. 3.315; RE 56.946-DF, DJ 31-3-65, p. 585; RE 54.305-PB, DI 26-11-64, p. 4.303; RE 57.129-RN, DI 14-9-66, p. 3.101; RE 37.212-DF, DJ 26-10-66, p. 3.748; RMS 14.581-RJ, RTJ 33/337; RE 46.500-PE, RTJ 24/324; RE 56.596-DF, RTJ 32/435). 
No mesmo sentido, o Tribunal Federal de Recursos com as decisões: AMS 28.763-CE, DI 28-4-64, p. 1.075; AMS 28.465GB, DI 28-4-64, p. 1.074; AMS 31.047, DI 14-7-64, p. 2.335; AMS 35.759 , DJ $17-3-65$, p. 377; Ap. 19.700, DJ 23-12-64, p. 4.677 .

Entretanto, "o estágio probatório não protege o funcionário contra a extinção do cargo" (Súmula 22; RMS 15.083-RJ, DJ 30-3-66, p. 989; RE 47.539-SP, DJ 17-12-63, p. 4.441; RMS 15.154-SP, RTJ 36/541).

Mesmo não tendo o inquérito, que se fêz depois, apurado falta grave, houve razões de conveniência para a dispensa de uma função, que era de confiança, não estando o recorrente amparado por qualquer espécie de estabilidade (RE 59.039-DF, RTJ 42/540).

Aplicação do art. 207, item V, da Lei n 1.711, de 1952. Nega-se provimento à apelação da sentença que julgou improcedente a ação de servidor público, demitido por ofensas físicas, em serviço, contra particular, na ausência de legitima defesa (Ap. 21.022-GB, DI 25-4-67, p. 1.115).

Demissão por extorsão no exercício do cargo.

Denega-se a segurança se o ato resultou de processo regular, sem qualquer eiva ou suspeita de abuso de poder (RMS 16.405SP, DI 15-2-67, p. 182).

Funcionário público não pode ser demitido por causa de proposição apresentada no exercício do mandato legislativo (AMS 38.622-GB, DJ 26-10-65, p. 2.942).

\section{2 - CASSAÇÃo DE APOSENTADORIA OU DISPONIBILIDADE}

Ocorre a punição de cassação de aposentadoria ou disponibilidade se ficar provado que o inativo:

I - Praticou falta grave no exercício do cargo ou função.

II - Aceitou, ilegalmente, cargo ou função pública;

III - Aceitou representação de Estado estrangeiro sem prévia autorização do Presidente da República;

IV - Praticou usura em qualquer de suas formas (art. 212 da Lei $n^{\circ}$ 1.711, de 1952).

Ao funcionário em disponibilidade, ainda, será cassada essa disponibilidade se não assumir, no prazo legal, o exercício do cargo ou função em que foi aproveitado (parágrafo único do cit. art. 212).

Entende o Supremo Tribunal Federal que o afastamento pela aposentadoria ou disponibilidade não tira do funcionário 
a condição de funcionário (RE 28.228, Rel. Min. Nelson Hungria, Rev. Forense V 169, p. 166/7).

Já o Tribunal Federal de Recursos proclama que "não se deve considerar a disponibilidade situação idêntico à aposentadoria. Nesta, o funcionário deixa o serviço público e torna-se pensionista do Estado, ao passo que, naquela fica ao dispor do Serviço Público, apenas afastado por circunstâncias que the são atribuiveis. Daí porque sua situação é, em tudo, igual à do funcionário em atividade" (Min. Oscar Saraiva, Ap. 7.497, D) 20-8-64, p. 2.949).

São decisões do Tribunal Federal de Recursos:

Cassação de aposentadoria. Prática de crime. Sem prova de fatos caracterizadores de figura penal, a que se comina pena ensejadora da demissão obrigatória do servidor público, não é possivel cassar-lhe a aposentadoria, máxime quando a própria Administração foi omissa em intentar contra êle processo crime".

Neste caso, houve voto vencido que entendia que:

"Decretou-se a aposentadoria, não obstante processo administrativo em andamento, para perquirição de acusações graves irrogadas à conduta funcional do funcionário. O processo feito com amplitude de defesa, resultou positivo".

Interpostos os embargos à apelação, foram os mesmos rejeitados, por maioria, para prevalecer a decisão (AP 15.788-RN, DJ 28-8-64, Apenso, p. 698; EAp. 15.788-RN, DJ 9-9-66, página 3.045 ).

"Aposentadoria uma vez concedida só pode ser cassada nas hipóteses previstas na Lei $n^{\circ} 1.711$, de 1952" (AMS 22.532-BA, DI 13-3-64, Apenso, p. 267).

“Aposentadoria. Seu cancelamento. - Existência de denúncia criminal - A decisão administrativa que concedeu aposentadoria prevalecerá até que sentença criminal definitiva faça cessar seus efeitos". (AMS 50.235-GB, DJ 21 12-66, p. 4.476).

\section{3 - SUSPENSÃO}

Têmo-la em duas categorias: Suspensão Preventiva e Suspensão Definitiva.

A primeira é medida provisória e discricionária e a segunda, penalidade. Só no caso de aplicação dessa última é que se impõe a prévia audiência do servidor (RMS 10.991-SP, DI 24 12-62, Apenso, p. 985). 
Assim,

"Para suspensão imposta sem inquérito administrativo regular e sem defesa do acusado. Nulidade do ato" (Ag. 36.310 GB, DI 27-5-66, p. 1.787).

"O funcionário suspenso, ao retornar a seu cargo, tem direito aos vencime correspondentes. Art. $225, \S 2$, do $\mathrm{EF}^{\prime}$ ( $\mathrm{Ag}$. 34.350-DF, DJ 17-11-65, p. 3.225).

No Tribunal Federal de Recursos a orientação tem-se firmado no sentido de que:

"Para imposição de pena disciplinar, que não ultrapasse a censura e a suspensão até 30 dias, é dispensável sindicância de forma regular; basta a simples constatação do ato violador da disciplina funcional para que tenha cabimento uma e outra". (AMS 54.247 GB, DJ 19 6 67, p. 1.888; AMS 31.151-RS, DI 20-6-66, p. 2.167; AMS 51.980-MG, DJ 21 10-66, p. 3.689; Ap. $15.845-\mathrm{GB}$, DJ 25 8-67, p. 2.571).

“Suspensão preventiva. Quando decorridos mais de três meses desde a suspensão do servidor, sem vencimento, a comissão de inquérito sequer inicia seus trabalhos, faz o funcionário jus à segurança para compelir a administração pagar-lhe os vencimentos abusivamente suspensos". (AMS 46.293-MA, DJ 2-6-67, p. 1.651).

"Afastamento. - Se o período de afastamento do servidor excede o total das penas aplicadas, deve êle reassumir o cargo". (AMS 56.650-SP, DJ 13 11 67, p. 3.736).

"A pena de suspensão não pode ultrapassar o limite de 30 dias fixados pelo art. 215 da Lei n 1.711, de 1952". (AMS 29.456-GB, DJ 19-12-63, p. 4.493).

\section{4 - PRISÃo ADMINISTRATIVA}

Os objetivos das duas penas: Prisão Administrativa (arti go 214, L. 1.711-52) e Suspensão Administrativa (art. 215) são diferentes. A prisão administrativa é medida de proteção à Fazenda Nacional, enquanto a Suspensão Preventiva visa a afastar o funcionário do serviço a fim de que não possa influir na apuração da falta disciplinar cometida.

Durante o periodo da prisão administrativa não pode o funcionário receber os vencimentos ou vantagens do cargo, salvo se reconhecida posteriormente sua inocência. Quando ao servidor suspenso preventivamente, não há inconveniente que lhe seja pago o vencimento durante o período. Já no caso da prisão preventiva, pronúncia por crime-comum ou denúncia por crime 
funcional ou ainda condenação por crime inafiançável em processo no qual não haja pronúncia, perceberá um têrço $(1 / 3)$ do vencimento, com direito à diferença, se absolvido (art. 122, III, Lei 1.711-52; Par. CGR 339-H, de 24-5-66 - DO 23-6-66, p. $6.800 / 1)$.

"Prisão administrativa decretada por autoridade competente e comunicada ao poder judiciário, obedecidos os pressupostos do art. 214 do EF, não há ilegalidade a ser sanada por meio de habeas corpus" (HC 42.556-DF, DI 4-11 65, p. 3.034, RTJ 34/596).

E esclarece o Tribunal Federal de Recursos, "instalada a Justiça Federal (Lei 5.010, de 30-5-66), ao titular local, deve ser encaminhada a comunicação (RC $120 *$ GB, DJ 7-2-67, p. 225).

“O funcionário público sob prisão preventiva. - Direito à percepção de um têrço". (AMS 46.904-PE, DJ 22-5-67, página 1.468$)$.

"Durante a suspensão preventiva legitima, deixa o funcionário de pérceber remuneração, em homenagem ao princípio de que não há direito ao vencimento sem o efetivo exercício do cargo". (AMS 52.807-PR, D/ $2 \sim 4-67$, p. 1.211).

"Prisão administrativa; é competente para determiná-la diretor de repartição". (RHC 1.356-SC, DJ 31-8-65, p. 2.197).

"O Diretor do DNER tal o preceito do art. 214 do Cap. VI do EF pode decretar a prisão administrativa de seus funcionários em casos previstos em lei". (HC 1.478-PA, DJ 16-9 de 1966, p. 3.136).

"Entendimento do art. 214 do EF. Reconhecimento da legitimidade da prisão, decretada dos indícios veementes de lesão ao Patrimônio Nacional". (HC 1.253, DI 1-6 65, p. 1.252).

"Prisão administrativa tem prazo máximo improrrogável: noventa dias (L. 1.711, art. 214, § $2^{\circ}$ )". (RHC 1.472-GB, D/ 21-10-66, p. 3.681).

"Prisão administrativa decretada por administrador de entidade autárquica (Caixa Econômica de São Paulo). Legitima-se no caso a aplicação do art. 214 do EF". (RHC 1.121-SP, DI $30-9-63$, p. 3.228).

"Concede-se a ordem quando a prisão administrativa é decretada por autoridade incompetente". (RHC 1.279, DJ 20-4-65, 785). 
"Prisão administrativa. Não deve atingir o receptador, se a receptação constitui crime autônomo". (HC 931 PI, DI 8-1-64, Apenso, p. 12).

"Não supre o depósito em molde a invalidar o decreto de prisão administrativa, a alegação da existência de seguro-fiança capaz de cobrir o alcance. Inteligência do $\S 22^{\circ}$ do art. 650 do Cód. de Proc. Penal". (HC 1.508-PR, DJ 14-10-66, p. 3.557).

\section{III - PENALIDADES \\ 5 - ATOS INSTITUCIONAIS}

A demissão com base no $\S 1^{\circ}$ do art. $7^{\circ}$ do Ato Institucional $\mathrm{n}^{9} 1$ está excluída da apreciação judicial (MS 14.611-DF, DJ 8-3-67, p. 487-HL; MS 14.818-DF, DJ 8-3-67, p. 487; MS 14.830-DF, DJ 8-3-67, p. 487; MS 14.983-DF, DJ 16-3-67, p. 576; MS 14.866-DF, DJ 8-3-67, p. 487; MS 14.884-DF, MS 14.914-DF, MS 14.917-DF, MS 14.943-DF, MS 15.014-DF e MS 15.904-DF, DJ 8 3-67, p. 488; MS 14.902-DF, DJ 29-9-67, p. 3.089).

Mandado de Segurança contra ato do Presidente da República, baseado no art. $7^{\circ}, \S 1 \%$, do A.I. de 9-4-64. Atos dessa natureza estão excluidos da apreciação judicial, pelo art. $19, \S 11^{\circ}$, do A.I. n 2 (MS 14.750-DF, DI 23-3-66, p. 868; MS 14.755DF, DJ 23-3-66, p. 868; MS 16.482-MG, DI 31-8-66, página 2.920; MS 14.875-DF, DJ 12-10-66, p. 3.509).

Exclusão da apreciação judicial - A.I. 2, art. 19, I, e artigo 173, I, da CF de 1967; MS 14.899-DF, DJ 26-4-67, página 1.134; 14.897-DF, DJ 26-4-67, p. 1.134; RTJ 41/317; 14.951-DF, DJ 26-4-67, p. 1.134; 14.944-DF, DJ 19-4-67, página $1.038 ; 14.930-\mathrm{DF}$, DJ $12-4-67$, p. $934 ; 14.861-\mathrm{DF}, D J$ 12 4-67, p. 934, RTJ 41/437; 14.938-DF, DJ 10-5-67, p. 1.316.

Servidor demitido com base nos Atos Institucionais. - A regra do art. 173 da Constituição de 1967 abrange os atos praticados sem observância das formalidades previstas no Decreto $n^{2} 53.897$, de 1964 .

Esta a jurisprudência do Tribunal Federal de Recursos (AMS 26.963-SP, DI 20-11 67, p. 3.852; AMS 26.881-SP, DJ 22-9-67, p. 2.976; AMS 26.882-SP, DI 29 9 67, p. 3.095).

Observância dos requisitos formais para validade dos atos decorrentes do exercício transitório do poder revolucionário. Interpretação do art. $7^{\circ}$ e $\S 4^{\circ}$ do A.I. 1 , bem como do art. $5^{\circ}$ do Dec. 53.839-64 (RMS 16.247-SP, RTJ 40/516). 
O acórdão objeto do presente recurso ordinário circunscreveu ao exame das formalidades extrínsecas, em obediência à regra insita no $\S 4^{\circ}$ do art. $7^{\circ}$ do A.I. 1 (RMS 16.870-RJ, 17.058-AM, DI 3-5-68, p. 1.490).

Contratado pelos têrmos da legislação do trabalho que passou, de acôrdo com a Lei $n^{\circ} 4.242-63$, à condição de servidor público, pode ser demitido na conformidade com o Ato Institucional (MS 14.910-DF, DJ 27-6-67, p. 2.013, RTJ 41/800).

A aposentadoria do funcionário, de acôrdo com o A.I. 1, não importa na aposentadoria previdenciária, se não atendidas, para esta, os requisitos previstos na legislação especial (RMS 18.794-GB, DJ 13-9-68, p. 3.556).

\section{ATOS INSTITUCIONAIS - APLICAÇÃO PELOS GOVERNADORES}

O Poder Judiciário tem fixado jurisprudência no sentido da possibilidade do seu contrôle jurisdicional limitar-se ao exame de formalidades extrínsecas, com relação à aplicação dos Atos Institucionais pelos Governadores, vedada, entretanto, a apreciação dos fatos que a motivaram, bem como de sua conveniência ou oportunidade.

Êsse o sentido das decisões:

"Dou provimento, em parte, ao recurso, para que - Tribunal de Justiça aprecie o pedido como fôr de direito. Já temos decidido que a vedação do A.I. 2, art. 19, II, não alcança os atos dos Governadores dos Estados: RMS 15.291 (23-9-65) RTJ 35/390; RMS 16.258 (4-10-66) RTJ 39/7; RMS 16.247 (27-10-66) RTJ 40/516; RMS 16.565 (28-11-66) RTJ 40/518; RMS 15.335 (2-12-66) RTJ 40/656; RMS 16.400 (28-11-66) RTJ 41/331; RMS 16.545 (14-10-66) RTJ 40/7; RMS 16.111 (10-10-66) RTJ 40/295; RMS $15.835(28-11-66)$. RTJ 40/461 (RMS 17.606 AM, RTJ 44/441).

"Não estão excluídas de apreciação pelo Poder Judiciário quanto às formalidades extrínsecas, os atos dos Governadores dos Estados, baseados no A.I. 1" (RE 61.330-RN, DJ 15-3-68, p. 734, RTJ 44/553; RMS 16.870-RJ, RTJ 44/623; RMS 17.606-AM, DJ 29-3-68, p. 987).

"Não estão imunes de apreciação pelo Poder Judiciário os atos dos governadores do Estado baseados no art. $7^{\circ}$ do A.I. 1 , especialmente quanto às formalidades 
extrínsecas. Só foram excluídos da apreciação da Justiça, pelo A.I. $n^{9} 2$, os atos praticados pelo Comando Supremo da Revolução e pelo Presidente da República, no plano federal, e os atos das Assembléias Legislativas e Câmaras de Vereadores, quanto à cassação de mandatos, nos planos estadual e municipal. Formalidades extrinsecas e descumpridas em investigação sumária procedida por comissão estadual de investigações. Demissão de servidor que tinha 38 anos de serviço, sem falta que o desabonasse, e pai de 23 filhos, dos quais 15 menores e sob sua dependência econômica. Recurso de mandado de segurança provido. Unânime. (RMS número 15.596 PI, DJ $19-12-66$, p. 4.443, RTJ $39 / 414$, DJ 20-2 67, p. 245).

Com a mesma orientação: RMS 15.335-PA, DJ 29-3-67, p. 712, RTJ 40/656; 17.070-AM, DI 1-12-67, p. 4.091).

Não cabe ao Judiciário apreciar o mérito (RMS 16.543-SP, DJ 19 12 66, p. 4.434, DJ 20-2 -67, p. 236, RTJ 39/350; RMS 16.689-RJ, DJ 1-12-67, p. 4.091; RMS 16.639-DJ, DI 10-5-67, p. 1.317; RMS 16.781; RJ, DJ 10-5-67, p. 1.312).

Mas, "satisfeitas as formalidades extrínsecas, não há cabimento para mandado de segurança" (RMS 16.527. AM, DJ 19-4-67, p. 1.038; RTJ 40/666; RMS 16.871 RJ, DJ 24-5-68, p 1.683; RMS 17.880-RJ, DJ 19-4-68, p. 1.256; RMS 16.810-RJ, DJ 19-4-68, p. 1.256).

"Funcionário municipal estável, demitido por ato do Governador de Estado, após investigação sumária. Incompetência do Poder Judiciário para anular o ato demissório e, em conseqüência, aposentar o servidor. Recurso provido, a fim de que o Tribunal de Justiça julgue o pedido nos têrmos do art. $7{ }^{\circ}, \S 44^{\circ}$, do A.I. 1" (RE 59.603-SP, RTJ 45/337).

"O contrôle das sanções aplicadas pelo Executivo, com base no art. $7^{\circ}$ do A.I. 1, limita - se às formalidades extrinsecas" (RMS 17.874-RJ, DJ 4-10-68, pági-
na 4.647).

Tem entendido o Supremo Tribunal Federal que são formalidades exigidas pelo art. $7^{\circ}, \S 1^{19}$, do A.I. 1:

a) a investigação sumária;

b) notificação do funcionário para defesa e oportunidade de sua apresentação (Tribunal Pleno, RE 
60.485-RN, RTJ 43/623; e RMS 16.874-RJ, DJ 31-5 de 1968 , p. 1.983; e RE $61.320-R N$, DJ 8-3-68, página 635); e

c) ato de demissão de autoridade competente.

Por outro lado, entendido também que:

"Ato Instiucional n' 1. Sua aplicação aos Estados. Medida de exceção. Dificuldade de estabelecer os limites da ação judicial. Não provimento, por não haver direito liquido e certo". (RMS 17.874-RJ, DJ 24-5-68, p. 1.864).

"Punição aplicada por Governador de Estado. Apreciação do ato pelo Judiciário. Problemas complexos e matéria de fato que devem ser examinados pelas vias ordinárias." (RMS 15.834-RS, DJ 19-4-67, página 1.038 , RTJ $40 / 461$ ).

"Inobservância de formalidades extrinsecas pela Comissão de Investigação. Cerceamento de defesa" (Min. Adalício Nogueira) - RMS 18.295-GB, DI 3-5 68, p. 1.491 .

"Improcedência da alegação de cerceamento de defesa segundo o Decreto 53.897-64" (Min. Aliomar Baleeiro - RMS 16.869-RJ, DJ 26-5-67, p. 1.526 .

Aposentadoria. Ato Institucional. Aplicação do Governador de Estado. Defesa garantida pelo direito federal e pelo estadual. Anulação do ato por inobservância de formalidades".

"Seria, pois, facílimo ao Estado comprovar que o recorrido fôra intimado para se defender. Como transferir êste ônus ao servidor que teria, então, de fazer prova negativa?"

(Tribunal Pleno - RE 60.485-RN, RTJ 43/623).

"O art. 7\% do A. I. 1 dava ao Governador do Estado o poder de aplicar as sanções nêle previstas aos servidores vitalícios e estáveis. Não permitia, entretanto, aplicar, como sanção, a reversão ao serviço ativo, para depois demitir o funcionário". Isto constituiria violação do próprio Ato Institucional. Deu-se, assim, provimento ao recurso do funcionário atingido pelo excesso de poder. (RMS 16.427-SP( RTJ 43/797).

Não há dúvida também de que os titulares das garantias constitucionais ou legais da vitaliciedade e estabilidade podem ser demitidos ou dispensados, postos em disponibilidade, aposen- 
tados, transferidos para a reserva ou reformados, com vencimentos e vantagens proporcionais ao tempo de serviço (A.I. $\mathrm{n}^{\circ}$ 1, art. $79^{\circ} \S 1^{\circ}$ ) (Min. Adaucto Lúcio Cardoso - RMS 17.720GO, DI 20-9-68, p. 3.699).

Assim é que "o contrôle judicial da legalidade de demissão com base no Ato Institucional $n^{\circ} 1$ era restrito à observância das formalidades extrínsecas dentre as quais a defesa efetiva do acusado". Entendendo, entretanto, que "não vicia a demissão o obstáculo criado à defesa pelo próprio acusado, que, sendo funcionário, não foi encontrado na repartição nem em sua residência, apesar de ai procurado por vêzes". Mas teve a defesa feita por curador dativo da Ordem dos Advogados. (Min. Aliomar Baleeiro - RE 63.752-DF, DI 27-9-68, p. 3.833).

Reconhece-se a inexistência de diretio liquido e certo em pedido de segurança para impedir o preenchimento de vaga decorrente da aposentadoria do Magistrado, decretada com fundamento nos arts. $7^{\circ}, \S 1^{\circ}$, e $8^{\circ}$. (RMS 16.542-SP, DI 3-5-68, p. 1.490).

"Demissão com base no Ato Institucional após a conclusão do inquérito com oportunidade de defesa. Provas realizadas na investigação não contestadas". (RMS 16.874-RJ, DI 31-5-68, p. 1.983).

"Demissão. Ato Institucional, art. 7\%. Investigação realizada pelo Tribunal de Justiça de Mato Grosso. Falta de liquidez e certeza. Mandado de segurança indeferido". (RMS 17.576-MT, DI 8-11-68, p. 4.647). "Estão excluídos da apreciação judicial as cassações de mandato de deputados estaduais, quando resultantes de resoluções da Assembléia Legislativa, tomadas no periodo compreendido entre 31 de março de 1964 e a data da promulgação do Ato Institucional n 2 (27 de outubro de 1965).

Direito a certidões para defesa:

"Ato Institucional. Certidões não fornecidas pela autoridade impetrada. Mandado de segurança em que se requereu a remessa das peças recursadas, tendo sido indeferido o pedido de requisição. Acórdão anulado para que as peças reclamadas sejam pedidas à autoridade, na forma do art. 6\%, parágrafo único, da Lei $\mathrm{n}^{\circ} 1.533$, de 31 de dezembro de 1951" (RMS 17.440RJ, DJ 31-5-68, p. 1.984, RTJ 45/224). nais.

No próximo número: IV - Anistia e V - Crimes Funcio-

WaLdYR DOS SANtos - Diretor da Divisão do Regime Juridico do Pessoal
do DASP. 